\title{
COMPARISON OF TWO DOSES OF OXYTOCIN FOR THE PREVENTION OF POSTPARTUM UTERINE ATONY IN PARTURIENTS UNDERGOING EMERGENCY CAESAREAN DELIVERY: A RANDOMIZED DOUBLE BLIND STUDY
}

Fayaz Ahmad Munshi', Yunus Mohammad², Masrat Jan³, Kashif Hassan', Mushtaq Ahmad ${ }^{5}$

${ }^{1}$ Associate Professor, Department of Anaesthesiology and Critical Care, Government Medical College, Srinagar.

${ }^{2}$ Senior Resident, Department of Anaesthesiology and Critical Care, Government Medical College, Srinagar.

${ }^{3}$ Senior Resident, Department of Anaesthesiology and Critical Care, Government Medical College, Srinagar.

${ }_{4}^{4}$ Post Graduate Scholar, Department of Anaesthesiology and Critical Care, Government Medical College, Srinagar.

${ }^{5}$ Senior Resident, Department of Anaesthesiology and Critical Care, Government Medical College, Srinagar.

\section{ABSTRACT}

\section{BACKGROUND}

The optimal dose of oxytocin at Caesarean section is unclear. Oxytocin may cause adverse cardiovascular effects including tachycardia and hypotension, whereas an inadequate dose can result in increased uterine bleeding. We compared the effects of two doses of oxytocin in a randomized double-blind trial.

\section{METHODS}

80 patients undergoing emergency Caesarean section received an IV bolus of either 2 or 5 units (u) of oxytocin after delivery, followed by an oxytocin infusion of $10 \mathrm{uh}^{-1}$. All patients received spinal anaesthesia with mean arterial pressure maintained by injection ephedrine. We compared changes in Heart Rate (HR), Mean Arterial Pressure (MAP), blood loss, uterine tone, the need for additional uterotonic drugs and antiemetics.

\section{RESULTS}

There was a greater increase in mean (SD) HR in patients who received $5 \mathrm{u}$ of oxytocin [32 (17) beats $\mathrm{min}^{-1}$ ] than in those who received $2 \mathrm{u}$ [24 (13) beats $\left.\mathrm{min}^{-1}\right](\mathrm{P}=0.015)$. There was a larger decrease in MAP in patients who received $5 \mathrm{u}$ [13 (15) $\left.\mathrm{mmHg}\right]$ than in those who received $2 \mathrm{u}[6(10) \mathrm{mmHg}](\mathrm{P}=0.030)$. The frequency of nausea and antiemetic use was higher after $5 \mathrm{u}(32.5 \%)$ than $2 \mathrm{u}(5 \%)(\mathrm{P}=0.003)$. There were no differences in blood loss, uterine tone or requests for additional uterotonic drugs $(17.5 \%$ in both groups).

\section{CONCLUSIONS}

In emergency Caesarean section, a 2 u bolus of oxytocin results in less haemodynamic change than $5 \mathrm{u}$ with less nausea and no difference in the need for additional uterotonics.

\section{KEYWORDS}

Anaesthesia, Haemodynamic, Uterotonic, Oxytocin, Caesarean Section.

HOW TO CITE THIS ARTICLE: Munshi FA, Mohammad Y, Jan M, et al. Comparison of two doses of oxytocin for the prevention of postpartum uterine atony in parturients undergoing emergency caesarean delivery: a randomized double blind study. J. Evolution Med. Dent. Sci. 2016;5(29):1500-1503, DOI: 10.14260/jemds/2016/353

\section{INTRODUCTION}

Although oxytocin is used to aid uterine contraction after delivery at Caesarean section, the optimal dose is unclear. $^{1-3}$ Oxytocin causes cardiovascular effects including tachycardia, hypotension and ST changes.1,2,4 and the IV administration of 10 units (u) of oxytocin has been reported to cause cardiovascular collapse and death. ${ }^{5}$ Although $5 \mathrm{u}$ is the recommended dose in the UK and Australia. ${ }^{6}$ the minimum effective bolus dose for $90 \%$ of patients (ED90) at elective Caesarean section has recently been estimated to be as low as 0.35 u. $^{7}$ However, it appears that many obstetricians remain unconvinced.

\section{Financial or Other, Competing Interest: None.}

Submission 20-02-2016, Peer Review 15-03-2016,

Acceptance 21-03-2016, Published 11-04-2016.

Corresponding Author:

Dr. Mushtaq Ahmad Rather,

Senior Resident,

Department of Anaesthesiology and Critical Care,

GMC, Srinagar-190006.

E-mail: mushtaqahmad767@gmail.com

DOI: $10.14260 /$ jemds/2016/353
A recent UK survey of 365 obstetricians and anaesthetists found that nearly all gave an initial 'Slow bolus' of at least 5 $u^{8}{ }^{8}$ followed by the selective use of an oxytocin infusion, most commonly at $10 \mathrm{uh}^{-1}$. Our clinical impression has been that a smaller bolus of $2 \mathrm{u}$ oxytocin followed by a routine infusion, produces adequate uterine contraction with fewer adverse effects than a larger bolus. So in the present study, we compared the haemodynamic and adverse effects of $2 \mathrm{u}$, compared with $5 \mathrm{u}$ of oxytocin when both were followed by an oxytocin infusion of $10 \mathrm{uh}^{-1}$.

\section{METHODS}

The study was approved by the Ethics Committee of the Lalla Ded Hospital, Srinagar. After written informed consent, 80 patients undergoing emergency Caesarean section under spinal anaesthesia received either 2 or $5 \mathrm{u}$ of IV oxytocin after delivery in a randomized double-blind fashion. Patients at increased risk of uterine atony or excessive bleeding (More than two previous Caesarean sections, a history of previous post-partum haemorrhage, known. 
Placenta praevia or accreta, twin pregnancy and polyhydramnios) or cardiovascular instability (Pre-eclampsia or essential hypertension) were excluded. In the operating theatre, IV access (18 gauge) was established, then multichannel monitor was applied for pulse oximetry, ECG and Non-Invasive Blood Pressure (NIBP) recordings. All patients received spinal anaesthesia in the sitting position with hyperbaric bupivacaine $0.5 \%(2.75 \mathrm{~mL}) ; 15 \mathrm{~mL} \mathrm{~kg}^{-1}$, Ringer lactate solution was then rapidly infused over 10-15 minutes with further IV fluids given at the discretion of the anaesthetist. Mean Arterial Pressure (MAP) within 10\% of the level before anaesthesia was maintained by injection ephedrine $5 \mathrm{mg}$ IV boluses. ${ }^{9}$

Measurement of NIBP was taken at 1 minute intervals from when the patient was laid supine until 10 minutes after delivery. Surgery was allowed once the neuraxial block height had reached T4 to cold perception. After delivery of the baby and cord clamping, the anaesthetist gave a $5 \mathrm{~mL}$ IV bolus of pre-prepared oxytocin (Syntocinon), over 5-10 seconds. From a series of random numbers in sealed envelopes, either $2 \mathrm{u}$ or $5 \mathrm{u}$ had been premixed in saline by a doctor not involved in the care of the patient or any data recordings, so that both anaesthetist and obstetrician were blinded to the oxytocin dose. Immediately after the bolus, a separate infusion of oxytocin $40 \mathrm{u}$ in 1 litre of Ringer lactate solution was commenced at $250 \mathrm{~mL} \mathrm{~h}^{-1}$ (i.e. $10 \mathrm{uh}^{-1}$ for $4 \mathrm{~h}$ ).

The placenta was delivered by controlled cord traction. Uterine tone was assessed by the obstetrician at 5, 10, 15 and $20 \mathrm{~min}$. on a five-point scale, where $1=$ atonic; $2=$ partial but inadequate contraction; $3=$ adequate contraction; $4=$ well contracted; and 5=very well contracted. Additional uterotonic drugs, if requested by the obstetrician were administered in the following order: $5 \mathrm{u}$ oxytocin, ergometrine $0.2 \mathrm{mg}$ (Both IV), then intramuscular carboprost $0.25 \mathrm{mg}$ (Prostodin). Blood loss was estimated by visual assessment of suction bottles and drapes. The occurrence of nausea or vomiting, both before and after the oxytocin bolus was assessed by patient's report and frequent direct questioning until the patient left the operating theatre and recorded as a binary outcome (Yes or no). Emetic symptoms were treated by correction of any hypotension, then if necessary with rescue antiemetics (One or more of IV metoclopramide $10 \mathrm{mg}$ or ondansetron $4 \mathrm{mg}$ ).

From previous studies.1,2 it was predicted that changes in HR would be more reliable than changes in MAP when using non-invasive monitoring, so the primary outcome was the maximum change in HR after oxytocin. All outcome measures including the need for additional uterotonic agents and blood loss were analysed using Chi-square, Fisher exact and Student t-tests. Sample size calculations were based on the data from Thomas and Colleagues. ${ }^{1}$ that is an HR difference between the groups of 7 beats $\mathrm{min}^{-1}$, with a standard deviation of 11 . So at a power of 0.8 and $\mathrm{P}<0.05,40$ patients were required for each group for an unpaired Student's t-test.

\section{RESULTS}

80 women were randomized and all completed the study. The patient characteristics of the two groups were similar with no significant differences in antiemetic requirements before oxytocin was given (Table 1).
Table 1

Patient characteristics and treatments before oxytocin bolus. Data presented as mean (Range) for age, mean (SD) or median (Range).

\begin{tabular}{|c|c|c|c|}
\hline & $\mathbf{2 ~ u ~ ( n = 4 0 ) ~}$ & $\mathbf{5 ~ u ~ ( n = 4 0 )}$ & P-value \\
\hline Age (yr.) & $\begin{array}{c}30.8 \\
(20-40)\end{array}$ & $\begin{array}{c}30.9 \\
(21-41)\end{array}$ & 0.889 \\
\hline Weight (kg) & $79.3(19.9)$ & $77.6(13.4)$ & 0.679 \\
\hline Parity & $1.5(0-6)$ & $1.5(0-7)$ & 0.748 \\
\hline Nausea & 5 & 8 & 0.546 \\
\hline Antiemetic treatment & 2 & 3 & 1.000 \\
\hline $\begin{array}{c}\text { HR before oxytocin } \\
\text { (Beats min }{ }^{-1} \text { ) }\end{array}$ & $76(14)$ & $72(14)$ & 0.285 \\
\hline $\begin{array}{c}\text { MAP before oxytocin } \\
\text { (mmH) }\end{array}$ & $93(10)$ & $91(11)$ & 0.432 \\
\hline $\begin{array}{c}\text { Table 1: Patient Characteristics and Treatments before } \\
\text { Oxytocin Bolus }\end{array}$ \\
\hline
\end{tabular}

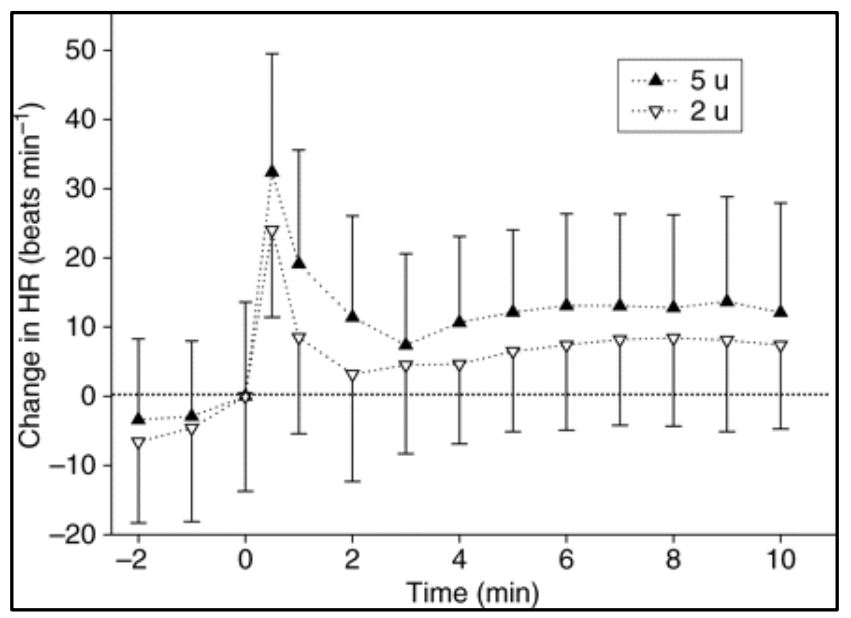

Fig. 1: Change in HR after Oxytocin Bolus (Time 0). Data Points shown are Mean and SD.

Table 2

Results after oxytocin bolus. Data, presented as mean (SD) or median (Range). Fluids given includes the amount before oxytocin; HR data- before 1 minute; MAP data- at 1 minute.

\begin{tabular}{|c|c|c|c|}
\hline & $2 \mathrm{u}(\mathrm{n}=40)$ & $5 \mathrm{u}(\mathrm{n}=40)$ & P-value \\
\hline $\begin{array}{l}\text { Fluids given } \\
(\mathrm{mL})\end{array}$ & $\begin{array}{c}2000 \\
(1000-3000)\end{array}$ & $\begin{array}{c}2000 \\
(1000-6500)\end{array}$ & 0.094 \\
\hline $\begin{array}{l}\text { Increase in HR } \\
\text { (beats min-1) }\end{array}$ & 24 (13) & $32(17)$ & 0.015 \\
\hline $\begin{array}{l}\text { Decrease in } \\
\text { MAP (mmHg) }\end{array}$ & $6(10)$ & $13(15)$ & 0.030 \\
\hline Nausea & 2 & 13 & 0.003 \\
\hline Vomiting & 1 & 6 & 0.108 \\
\hline $\begin{array}{l}\text { Antiemetic } \\
\text { treatment }\end{array}$ & 2 & 13 & 0.003 \\
\hline Blood loss & $\begin{array}{c}500 \\
(150-1200)\end{array}$ & $\begin{array}{c}500 \\
(200-2000)\end{array}$ & 0.889 \\
\hline $\begin{array}{c}\text { Additional } \\
\text { uterotonic } \\
\text { treatment at } 5 \\
\text { min. }\end{array}$ & 2 & 3 & 1.000 \\
\hline $\begin{array}{c}\text { Additional } \\
\text { uterotonic } \\
\text { treatment } \\
\text { overall }\end{array}$ & 7 & 7 & 1.000 \\
\hline
\end{tabular}




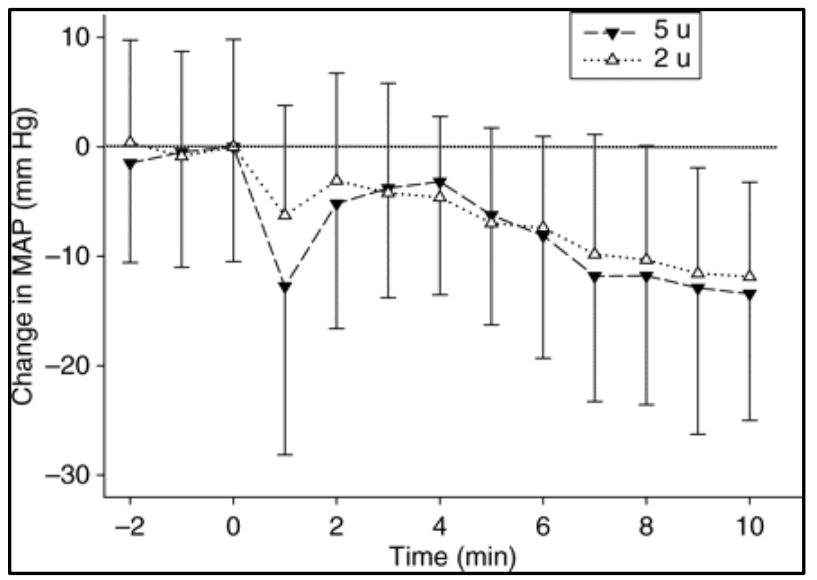

Fig. 2: Change in MAP after Oxytocin Bolus (Time 0). Data Points shown are Mean and SD.

After oxytocin, there was a significant increase from baseline in $\mathrm{HR}$ ( $\mathrm{P}=0.001$ for both groups). The greatest change in HR usually occurred at 1 minute after the oxytocin bolus and was greater in the $5 \mathrm{u}$ than the $2 \mathrm{u}$ group (Table 2); 23 patients $(57.5 \%)$ who received $5 \mathrm{u}$ had an HR increase of over 30 beats min $^{-1}$ compared with 11 patients (27.5\%) who received $2 \mathrm{u}(\mathrm{P}=0.012)$. After an initial recovery, the HR again increased significantly from baseline after 4 minutes in the 5 $\mathrm{u}$ group and after 5 minutes in the $2 \mathrm{u}$ group (Fig. 1). There was a significant decrease in MAP from baseline at 1 minute in both groups $(\mathrm{P}<0.005)$, which was greater in the $5 \mathrm{u}$ than the $2 \mathrm{u}$ group (Table 2). Six patients $(15 \%)$ who received $5 \mathrm{u}$ had a decrease in MAP of more than $30 \mathrm{mmHg}$ compared with none who received $2 \mathrm{u}(\mathrm{P}=0.026)$. After an initial recovery, the MAP again decreased significantly from baseline in both groups after 5 min (Fig. 2).

Thirteen patients $(32.5 \%)$ reported nausea and received antiemetic treatment after $5 \mathrm{u}$ oxytocin compared with 2 patients (5\%), who received $2 u$ (Table 2). The difference in vomiting frequency was not statistically significant (Table 2). There were no differences between the groups in blood loss, uterine tone at any measurement time or in the requirement for additional uterotonic drugs (Table 2). Cumulatively more patients required uterotonic treatment over the study period: 5 patients $(6.25 \%)$ needed additional uterotonics at 5 minutes; by $20 \mathrm{~min}, 14$ patients $(17.5 \%)$ had required treatment (Table 2). A total of 9 doses of additional uterotonics were required in the $2 \mathrm{u}$ group compared with 17 doses in the $5 \mathrm{u}$ group. However, 8 of these were for two patients in the $5 \mathrm{u}$ group, who also needed surgical treatment for persistent hypotonia and excessive blood loss. In one patient, who needed a B-lynch suture, the reason for the lack of response was unclear; in the second who required hysterectomy, placenta accreta was later found on histology.

\section{DISCUSSION}

Although maternal haemodynamic changes after delivery at Caesarean section have many potential causes including removal of aortocaval compression, autotransfusion from uterine contraction, blood loss, vasopressors and emotional excitement, previous studies have shown that uterotonic drugs are a dominant factor. 1,2 The most consistent cardiovascular changes observed after oxytocin are a doserelated decrease in arterial pressure due to peripheral vasodilation with a compensatory increase in HR and cardiac output.1,2,10,11 We found that an IV bolus of $2 \mathrm{u}$ oxytocin at Caesarean section resulted in less haemodynamic change than a $5 \mathrm{u}$ bolus. The increase in HR was significantly greater and more prolonged after $5 \mathrm{u}$ than after $2 \mathrm{u}$. The mean decrease in MAP was also significantly greater in the $5 \mathrm{u}$ group with 6 patients (15\%) sustaining a decrease of more than $30 \mathrm{mmHg}$ compared with none in the $2 \mathrm{u}$ group. Thomas and Colleagues. ${ }^{1}$ using invasive pressure monitoring found a decrease in MAP of $14 \mathrm{mmHg}$ at 1 minute after a $5 \mathrm{u}$ bolus, but with a maximum decrease of $27 \mathrm{mmHg}$ at 25 seconds. We observed an almost identical mean decrease of $13 \mathrm{mmHg}$ at 1 minute after $5 \mathrm{u}$ when measured by NIBP, so it is likely that the maximum decrease in MAP was underestimated in our study. Although maternal death has been attributed to the effects of a $10 \mathrm{u}$ bolus of oxytocin. ${ }^{5}$ catastrophic outcomes appear rare.

The (Usually transient) haemodynamic effects may only be important in the event of pre-existing heart disease or hypovolaemia, when patients may be unable to compensate for the sudden vasodilation. ${ }^{4,5}$ As we found significant changes even after a $2 \mathrm{u}$ bolus, an even smaller initial bolus or an oxytocin infusion alone might be a safer option in these situations. One clear advantage we observed after $2 \mathrm{u}$ compared with $5 \mathrm{u}$ was a marked decrease in the frequency of nausea and the need for antiemetic therapy (5\% vs $32.5 \%$ ). This may reflect the degree of sudden haemodynamic change, as the incidence of nausea is correlated to the degree of hypotension at Caesarean section. ${ }^{12}$ If this finding is confirmed in subsequent studies, this benefit on its own is enough to recommend the use of $2 \mathrm{u}$ in preference to $5 \mathrm{u}$ for emergency Caesarean section. Although decreasing (Or omitting) the oxytocin bolus minimizes haemodynamic changes. ${ }^{1,2}$ many doctors may be cautious about doing so because of concerns about poor uterine contraction and resultant increased bleeding. ${ }^{8}$

The assessment of uterotonic efficacy at Caesarean section has been attempted by estimation of blood loss, the measurement of postoperative haemoglobin, assessment of uterine tone and requests for supplementary uterotonic drugs. The last two measures, though subjective, appear to be more sensitive and less likely to be confounded by other causes of obstetric bleeding. For instance, two studies comparing different oxytocin regimens at Caesarean section with 694 and 321 patients reported differences in uterine tone and the need for further uterotonics, but were unable to detect differences in blood loss or change in haemoglobin. ${ }^{3,13}$ We found no differences between the groups in blood loss, uterine tone or the need for further uterotonics.

However, we did find a tendency for the initial uterotonic effect to 'wear off' in both groups, as the need for further uterotonic drugs increased from $6.25 \%$ of patients at 5 minutes to $17.5 \%$ by 20 minutes. This is in accordance with oxytocin's short half-life of $10-15$ min. ${ }^{14}$ but also implies that the initial infusion rate of $10 \mathrm{uh}^{-1}$ may be insufficient. Our results therefore do not agree with those of Carvalho and Colleagues. ${ }^{7}$ who in a dose-finding study of 40 patients estimated the ED90 of oxytocin at elective Caesarean section to be only $0.35 \mathrm{u}$ and found no need for further roxytocin with a maintenance infusion of $2.4 \mathrm{uh}^{-1}$. Although the reasons for the disparity are unclear, it appears that unlike our study they did not re-assess uterine tone after an initial response was achieved. ${ }^{7}$ 
As an alternative to an oxytocin bolus plus infusion, the long-acting oxytocin analogue carbetocin has potential benefits in terms of convenience and a decreased need for further uterotonics. ${ }^{15}$ In a large Caesarean section study, a $100 \mathrm{mg}$ bolus of IV carbetocin was compared with a $5 \mathrm{u}$ oxytocin bolus followed by a $2.5 \mathrm{uh}^{-1}$ infusion. ${ }^{13}$ Carbetocin resulted in fewer requests for additional uterotonics $(4.7 \%$ compared with $10.1 \%$ ) with a comparable incidence of nausea, but a greater decrease in arterial pressure. ${ }^{13}$ Further research is needed to determine whether a smaller oxytocin bolus dose and a faster infusion rate would result in a more favourable balance of efficacy and side-effects. The uterine responsiveness may be greatly decreased in emergency Caesarean section, therefore higher doses of oxytocin are often required and the early use of alternative uterotonics (e.g. ergometrine) may be preferable.3,16 In conclusion, we found that at emergency Caesarean section, $2 \mathrm{u}$ of IV oxytocin results in less haemodynamic change than $5 \mathrm{u}$ with less nausea and no difference in the need for additional uterotonic drugs.

\section{REFERENCES}

1. Thomas JS, Koh SH, Cooper GM. Haemodynamic effects of oxytocin given as i.v. bolus or infusion on women undergoing caesarean section. Br J Anaesth 2007;98:1169.

2. Pinder AJ, Dresner $\mathrm{M}$, Calow $\mathrm{C}$, et al. Haemodynamic changes caused by oxytocin during caesarean section under spinal anaesthesia. Int $\mathrm{J}$ Obstet Anesth 2002;11(3):156-9.

3. Munn MB, Owen J, Vincent R, et al. Comparison of two oxytocin regimens to prevent uterine atony at cesarean delivery: a randomized controlled trial. Obstet Gynecol 2001;98(3):386-90.

4. Svanstro"m MC, Biber B, Hanes M, et al. Signs of myocardial ischaemia after injection of oxytocin: a randomized double-blind comparison of oxytocin and methylergometrine during caesarean section. Br J Anaesth 2008;100(5):683-9.
5. RCOG. Why mothers die 1997-1999. Report on confidential enquiries into maternal deaths in the United Kingdom. London: RCOG Press 2001;134-49.

6. British national formulary. London: BMJ publishing group Itd and RPS publishing 2007;54 th edn:415-6.

7. Carvalho JC, Balki M, Kingdom J, et al. Oxytocin requirements at elective cesarean delivery: a dose-finding study. Obstet Gynecol 2004;104(5 pt 1):1005-10.

8. Wedisinghe L, Macleod M, Murphy DJ. Use of oxytocin to prevent haemorrhage at caesarean section-a survey of practice in the united kingdom. Eur J Obstet Gynecol Reprod Biol 2008;137(1):27-30.

9. Ngan Kee WD, Khaw KS. Vasopressors in obstetrics: what should we be using? Curr Opin Anaesthesiol 2006;19(3):238-43.

10. Secher NJ, Arnsbo P, Wallin L. Haemodynamic effects of oxytocin (syntocinon) and methyl ergometrine (methergin) on the systemic and pulmonary circulations of pregnant anaesthetized women. Acta Obstet Gynecol Scand 1978;57(2):97-103.

11. Petersson M. Cardiovascular effects of oxytocin. Prog Brain Res 2002;139:281-8.

12. Ngan Kee WD, Khaw KS, Ng FF. Comparison of phenylephrine infusion regimens for maintaining maternal blood pressure during spinal anaesthesia for caesarean section. Br J Anaesth 2004;92(4):469-74.

13. Dansereau J, Joshi AK, Helewa ME, et al. Double-blind comparisonof carbetocin versus oxytocin in prevention of uterine atony after cesarean section. Am J Obstet Gynecol 1999;180(3 pt 1):670-6.

14. Gonser M. Labor induction and augmentation with oxytocin: pharmacokinetic considerations. Arch Gynecol Obstet 1995;256(2):63-6.

15. Su LL, Chong YS, Samuel M. Oxytocin agonists for preventing postpartum haemorrhage. Cochrane Database Syst Rev 2007;18(3):CD005457.

16. Balki M, Ronayne M, Davies S, et al. Minimum oxytocin dose requirement after cesarean delivery for labor arrest. Obstet Gynecol 2006;107(1):45-50. 